\title{
Calcifying Fibrous Pseudotumor versus Inflammatory Myofibroblastic Tumor: A Histological and Immunohistochemical Comparison
}

\author{
Kalisha A. Hill, M.D., Frank Gonzalez-Crussi, M.D., Pauline M. Chou, M.D. \\ Department of Surgical Pathology, Children's Memorial Hospital, Northwestern University, \\ Chicago, Illinois
}

Calcifying fibrous pseudotumor (CFP), a recently described lesion, is characterized by a predominantly lymphoplasmacytic infiltrate with abundant hyalinized collagen and psammomatous or dystrophic calcifications. The cause and pathogenesis are unclear, but it has been postulated that CFP may represent a sclerosing end stage of inflammatory myofibroblastic tumor (IMT). We compared the histological and immunohistochemical profiles of seven cases diagnosed as CFP and seven as IMT. Histologically, the CFP demonstrated varying degrees of calcifications in addition to fibroblastic proliferation admixed with inflammatory cells composed of lymphocytes, eosinophils, and mast cells. The IMTs rarely contain calcifications and had a myofibroblastic proliferation varying from hyalinized acellular collagen to florid fibroblastic proliferations simulating sarcoma. The inflammatory component was composed primarily of plasma cells and lymphocytes, sometimes arranged as lymphoid aggregates with germinal centers. All CFP cases were diffusely positive for factor XIIIa and negative for smooth muscle actin, muscle-specific actin, and CD34. All IMTs demonstrated diffuse positivity for actin, variable positivity for CD34, and focal positivity for Factor XIIIa. This study demonstrates certain distinct histologic, immunohistochemical, and electron microscopic features between IMTs and CFPs.

Copyright $(2001$ by The United States and Canadian Academy of Pathology, Inc.

VOL. 14, NO. 8, P. 784, 2001 Printed in the U.S.A.

Date of acceptance: March 30, 2001.

Previously presented at the 89th Annual Meeting of the United States and Canadian Academy of Pathology, March 25-31, 2000, New Orleans, Louisiana.

This work was supported by a grant from Illinois Public Aid (PC).

Address reprint requests to: Pauline Chou, M.D., Department of Pathology, Box 17, Children's Memorial Hospital, 2300 Children's Plaza, Chicago, IL 60614; e-mail: pmchou@nwu.edu; fax: 773-880-8127.
KEY WORDS: Calcifying fibrous pseudotumor, Dendritic cell, Factor XIIIa, Inflammatory myofibroblastic tumor, Myofibroblast-CD34, Soft tissue tumor.

Mod Pathol 2001;14(8):784-790

Calcifying fibrous pseudotumor (CFP) is an uncommon benign fibrous lesion originally described as a collection of dense hyalinized collagenous tissue interspersed with benign-appearing spindle cells, psammomatous or dystrophic calcifications, and a variable, but usually lymphoplasmacytic inflammatory infiltrate (1). These lesions were reported initially as "childhood fibrous pseudotumor with psammoma bodies" (2). The term calcifying fibrous pseudotumor was coined by Fetsch et al. in 1993 (1), who reported this lesion in 10 patients ranging in age from 1 to 33 years. Recently, it has been postulated that CFP may represent a sclerosing end stage of inflammatory myofibroblastic tumor (IMT; 3). IMTs, also referred to by some authors as inflammatory pseudotumors, are tumorlike masses whose nature has been controversial. They have been thought to be either inflammatory or neoplastic. Recent cytogenetic study in IMT (4) favors the latter hypothesis, whereas the chromosomal characteristics of CFP have not been examined. We studied seven CFPs and seven IMTs and compared their histological, electron-microscopic, and immunohistochemical profiles in an attempt to better characterize their respective diagnostic features.

\section{MATERIALS AND METHODS}

Seven cases diagnosed as IMT and seven cases from six patients diagnosed with CFP were identified from the files of Children's Memorial Hospital and from the files of the Armed Forces Institute of Pathology. Material consisting of hematoxylin and eosin-stained sections on all cases were reviewed by two of us (PC and KH). Formalin-fixed, paraffinembedded tissue was available on all cases. Primary 
antibodies were directed against vimentin (DAKO; Glostrup, Denmark), desmin (DAKO), Factor XIIIa (Calbiochem-Novabiochem; San Diego, CA), CD34/Qbend (Biogenex; San Ramon, CA), cytokeratin AE1/AE3 (DAKO), c-kit/CD77 (Oncogene Science, Inc., Uniondale, NY), CD68 (DAKO), EBVLMP1 (DAKO), smooth muscle actin -clone 1A4 (DAKO), and muscle-specific actin HHF35 (ENZO Diagnostics, Farmingdale, NY). Clinical information was obtained from the medical records of the patients. Material was fixed in $2 \%$ glutaraldehyde, postfixed in $2 \%$ osmium tetroxide, and processed for electron microscopic study using conventional techniques.

Microvascular density (MVD) was determined by counting all CD34 positive vessels in 10 random high-power fields in a blinded fashion as previously reported (5).

\section{RESULTS}

\section{Clinical Information}

Of the seven IMT cases, there were three female patients and three male patients. Six were primary lesions. One additional case was a recurrent lesion (Case 6). The age at presentation ranged from 3 months to 16 years. The mean age at the time of surgery was 8.0 years. The lesions were located in the heart (Cases 1 and 2), orbit (Case 3), pancreas (Case 4), multifocal thoracic lesions (mediastinum, diaphragm, pericardium, and lung, Cases 5 and 6), and chest wall (Case 7). All cases were treated with surgical resection. One patient died because of surgical complications (heart lesion, Case 2), and another patient was lost to follow up (chest wall lesion). See Table 1.

The CFP patients consisted of five male patients and one female patient, the latter with two separate lesions (Case 8 and 9). The patients ranged in age from 5 weeks to 13 years. The mean age at time of surgery was 2.9 years. The lesions were located in the superficial soft tissue of the neck (Cases 8, 9, and 10), subscapular region (Case 11), upper arm (Case 12), lower back (Case 13), and anterior thigh (Case 14). All cases presented as masses palpable on physical examination and were treated with surgical resection. No recurrences were noted except for the female with the submandibular lesion (Case 2) which recurred 4 months after incomplete removal. The histology of the recurrence was similar to that of the primary lesion. The patient is currently alive and well and has no complications.

\section{Pathology}

\section{Gross Findings}

The CFPs measured 0.5 to $3.5 \mathrm{~cm}$ in largest diameter and were well circumscribed, tan gray, and solid, some with myxoid changes, and a rubbery consistency. Some cases were received with an ellipse of skin, suggesting a superficial location, whereas others were deep to the subcutaneous tis-

TABLE 1. Clinicopathologic Characteristics

\begin{tabular}{|c|c|c|c|c|c|c|c|c|c|c|}
\hline $\begin{array}{l}\text { Case } \\
\text { No. }\end{array}$ & Age/Sex & Presenting Diagnosis & Location & $\begin{array}{l}\text { Factor } \\
\text { XIIIa }\end{array}$ & HHF-35 & CD34 & Desmin & Vimentin & CD68 & Outcome \\
\hline \multicolumn{11}{|l|}{ IMT: } \\
\hline 1 & $10 \mathrm{mo} / \mathrm{F}$ & $\begin{array}{l}\text { Atrial septal defect, left } \\
\text { atrial compression }\end{array}$ & Heart & $\mathrm{F}+$ & - & + & - & + & + & $A \& W 13$ yrs \\
\hline 2 & $3 \mathrm{mo} / \mathrm{F}$ & $\begin{array}{l}\text { Respiratory distress, } \\
\text { intraventricular septal } \\
\text { mass found on echo }\end{array}$ & Heart & $\mathrm{F}+$ & - & + & - & ND & $\mathrm{F}+$ & $\begin{array}{l}\text { Died during } \\
\text { operation }\end{array}$ \\
\hline 3 & $10 \mathrm{yr} / \mathrm{M}$ & $\begin{array}{l}\text { Paraneoplastic } \\
\text { syndrome, ptosis, } \\
\text { strabismus }\end{array}$ & Right orbit & + & + & - & + & ND & ++ & $\begin{array}{l}\text { Alive with } \\
\text { disease }\end{array}$ \\
\hline 4 & $16 \mathrm{yr} / \mathrm{F}$ & Jaundice, pleuritis & Pancreas & + & + & + & + & + & ++ & A\&W 10 yrs \\
\hline 5 & $13 \mathrm{yr} / \mathrm{M}$ & Pneumonia & Thorax & $\mathrm{D}+$ & + & - & + & $\mathrm{D}+$ & $+/ \mathrm{M}$ & $\begin{array}{l}\text { Recurred } \\
\text { within } 6 \text { mo }\end{array}$ \\
\hline 6 & $13 \mathrm{yr} / \mathrm{M}$ & Recurrence & Thorax & $\mathrm{F}+$ & + & + & - & $\mathrm{D}+$ & $+/ \mathrm{M}$ & A\&W 1 yr \\
\hline 7 & $3 \mathrm{yr} / \mathrm{M}$ & $\begin{array}{l}\text { Anemia, salmonella } \\
\text { bacteremia, } \\
\text { pneumonia }\end{array}$ & Chest wall & + & + & - & + & $\mathrm{D}+$ & ++ & $\begin{array}{l}\text { Lost to follow- } \\
\text { up }\end{array}$ \\
\hline \multicolumn{11}{|l|}{ CFP: } \\
\hline 8 & $5 \mathrm{wk} / \mathrm{F}$ & Supraclavicular mass & Rt neck & $\mathrm{D}+$ & - & - & - & $\mathrm{D}+$ & + & $\mathrm{A} \& \mathrm{~W} 6 \mathrm{mo}$ \\
\hline 9 & $5 \mathrm{wk} / \mathrm{F}$ & Submandibular mass & Rt neck & $\mathrm{D}+$ & - & $*_{\mathrm{f}}$ & - & $\mathrm{D}+$ & ++ & $\begin{array}{l}\text { Recurred } \\
\quad \text { within } 5 \text { mo }\end{array}$ \\
\hline 10 & $13 \mathrm{yr} / \mathrm{M}$ & Neck mass & Neck & + & - & $*_{\mathrm{f}}$ & $\mathrm{F}+$ & + & $\mathrm{F}+$ & $A \& W$ \\
\hline 11 & $1 \mathrm{yr} / \mathrm{M}$ & Subscapular mass & Subscapular & $\mathrm{D}+$ & - & - & - & + & ND & $A \& W$ \\
\hline 12 & $3 \mathrm{yr} / \mathrm{M}$ & Right upper arm mass & Rt upper arm & $\mathrm{D}+$ & - & - & - & + & ND & $A \& W$ \\
\hline 13 & $1 \mathrm{yr} / \mathrm{M}$ & Back mass & Back & + & - & - & - & + & ND & $\mathrm{A} \& \mathrm{~W} 47 \mathrm{mo}$ \\
\hline 14 & $2 \mathrm{yr} / \mathrm{M}$ & Left anterior thigh mass & $\begin{array}{l}\text { Lt anterior } \\
\text { thigh }\end{array}$ & $\mathrm{D}+$ & - & $*_{\mathrm{f}}$ & - & ND & ND & A\&W 15 mo \\
\hline
\end{tabular}

echo, echocardiography; A\&W, alive and well; F, focally positive; + , positive; $\mathrm{D}+$, diffusely positive; ${ }^{*}$, focally only at the advancing edge but negative elsewhere except around vessels; ND, not done; +/M, positive also macrophages. 
sue without skin attachment. The IMTs were all deep masses, involving organs or soft tissues, ranging in size from 0.2 to $10.0 \mathrm{~cm}$. The lesions were described as solid, irregular, grayish or tan-pink, firm tissue.

\section{Microscopic Findings}

Microscopic examination of the CFPs showed muscle and adipose tissue infiltrated by spindle cells arranged in an irregular fascicular pattern. The lesions entrapped muscle as well as nerve bundles (Fig. 1A). Dense hyalinized collagen was noted with an inflammatory infiltrate (Fig. 1B) consisting predominantly of lymphocytes and plasma cells. Eosinophils, neutrophils, and mast cells were present in variable numbers. Calcifications were dystrophic, ossifying, or psammomatous (Fig. 1C). No necrosis, atypia, or mitoses were noted.

Microscopic examination results of the IMTs were quite variable. There were compact dense fibrous tissues with lymphoid aggregates (Fig. 1D) with occasionally germinal centers. Plasma cells, some with Russell bodies and eosinophils, were also present. Some cases, particularly those of the thoracic and chest lesions (Cases 12, 13, and 14) were more cellular (Fig. 1E) and contained mitoses. No calcifications were noted.

Immunohistochemically, the spindle cells of the CFP showed diffuse cytoplasmic staining with antibodies against Factor XIIIa (Fig. 1F), CD68, and vimentin. Smooth muscle actin, muscle-specific actin, desmin and cytokeratin were negative in all cases of CFP. CD34 antibody stained the endothelial cells and focal localized fibroblasts, especially in areas where the lesion infiltrated normal structures. Whether these represented small capillaries with collapsed lumen is uncertain. Numerous CD77positive mast cells were noted.

The IMTs stained positively for muscle-specific actin (Fig. 1G), smooth muscle actin, and desmin (Fig. 1H) (except the two heart lesions, which had limited paraffin embedded tissue), as well as vimentin. CD34 staining is variable. Many proliferated myofibroblasts were stained in some cases, whereas others showed vessel staining only. As well, there were few c-kit-positive mast cells, adjacent to lymphoid follicles. Factor XIIIa was focally positive $(<10 \%$ of surface area examined) in all cases, except the thoracic and chest wall lesions, in which staining was somewhat more extensive $(<25 \%)$. CD68 was diffusely positive and showed numerous infiltrating macrophages in some cases as well. EBVLMP1 was not detectable in either CFPs or IMTs.

By electron microscopy, the spindle cells of CFP were consistent with immature fibroblasts. The presence of free ribosomes in helicoidal configuration was in keeping with the immaturity of these cells. There were also abundant collagen fibrils in the extracellular space, in close apposition to the fibroblasts. The latter showed irregularly arranged intermediate filaments, probably vimentin, in the cytoplasm (Fig. 2A).

The IMTs contained abundant capillaries with prominent endothelial cells, well-differentiated, spindle-shaped fibroblasts; plump mesenchymal cells consistent with "activated" fibroblasts; macrophages; and numerous plasma cells. Filamentous bundles, attachment densities, pinocytotic vesicles, and basal laminae were noted, consistent with myofibroblasts (Fig. 2B). The plump activated stromal cells showed highly developed organelles, abundant Golgi vesicles, rich endoplasmic reticulum, and lysosomes. These cells were identified as fibroblastic in view of their close and constant relationship with collagen bundles and other components of the intercellular matrix. A few mesenchymal cells showed an occasional stereocilium.

Microvascular density determined by counting CD34-positive cells showed a high vascular count in cases of CFPs, ranging from 95 to 139 per $5 \mathrm{hpf}$ in CFPs. In contrast, a wider range and more variability of microvascular density was noted in IMTs.

\section{DISCUSSION}

This article reported distinct histological and immunohistochemical features of CFP and IMT. Both IMT and CFP were initially considered to be lesions of young children. However, Fetsch et al. (1) described the occurrence of CFP in patients between 1 and 33 years of age (mean age, 16.2 years), with a slight predilection for females. Our Cases 8 and 9 were previously reported (6). Both lesions occurred in a 5-week-old female, suggesting a possible prenatal inception. In general, IMT patients were slightly younger (mean age, 9.7 years), and the lesion affected males and females equally (7). CFP usually presents as a mass in an otherwise healthy patient and is rarely multifocal (1), whereas IMT patients may have other symptoms or signs such as fever, pain, weight loss, malaise, anemia, thrombocytosis, increased sedimentation rate, and hypergammaglobulinemia (7). CFP has been described in the soft tissues of the trunk, limbs, peritoneum, epididymis, neck, pleura, chest wall, and mediastinum (1, 3, 8-14) as well as within a lesion of Castleman disease (15). IMT was originally described in the lung (16) as "plasma cell granuloma." Many other locations have been documented since (7).

CFP is described as a dense collection of hyalinized fibrosclerotic tissue with an inflammatory infiltrate chiefly composed of lymphocytes, plasma cells, and to a lesser extent, eosinophils, neutrophils, and mast cells (1). These masses may entrap muscle and nerves and contain psammomatous 

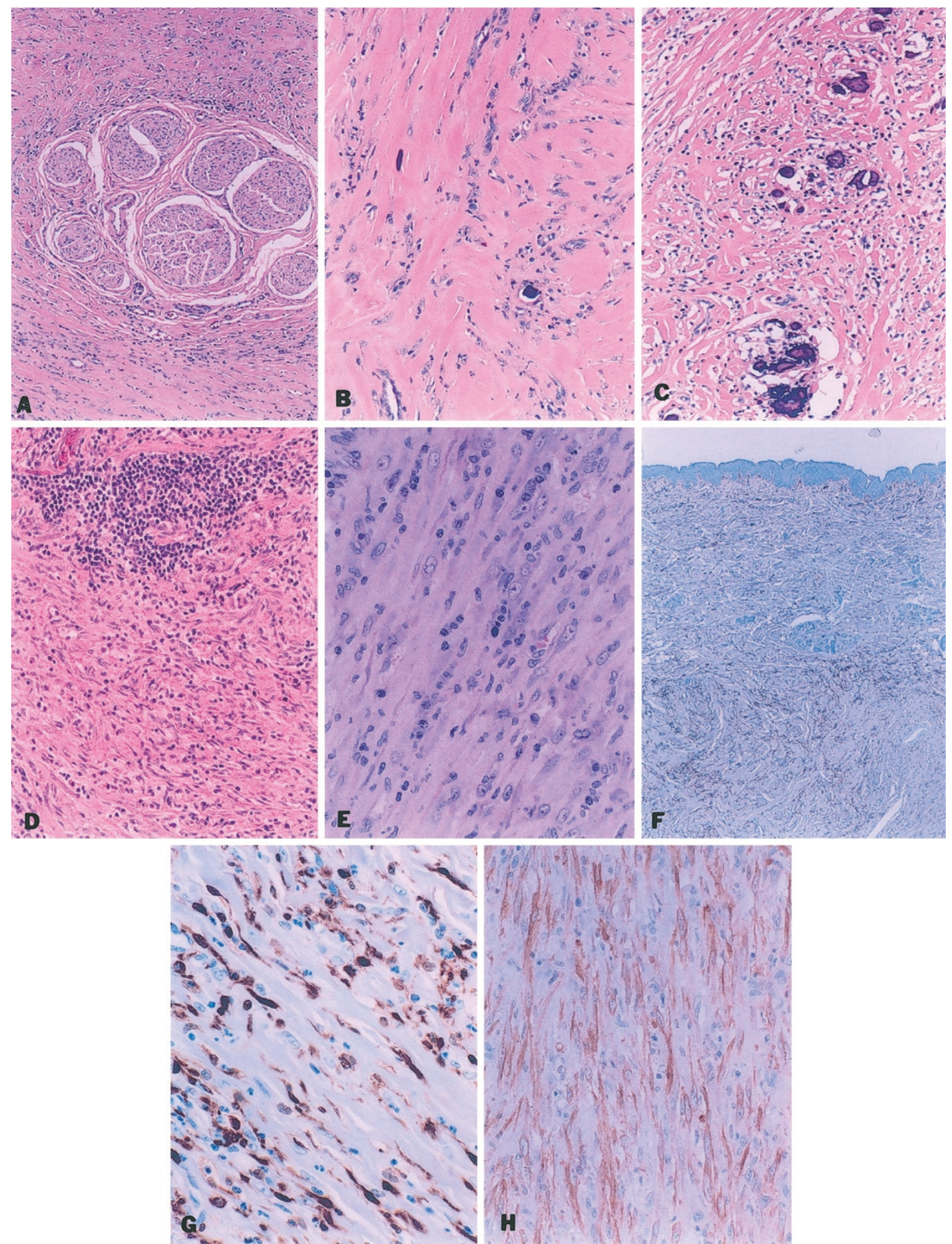

FIGURE 1. A, the dense hyalinized collagen of calcifying fibrous pseudotumor (CFP) surrounds a nerve bundle in the subcutaneous tissue of the skin. B, dystrophic, ossifying, and psammomatous calcifications are present in this CFP. C, inflammatory myofibroblastic tumor (IMT) contains dense fibrous tissue with inflammatory infiltrate and a lymphoid aggregate. D, a predominance of lymphocytes and plasma cells, admixed with spindled myofibroblastic cells, comprise this IMT. A mitotic figure is present in the center of the lesion. E, the spindle cells of CFP stained positive with Factor XIIIa, delineating the tumor from the upper dermis. F, diffuse cytoplasmic staining of the CFP spindle cells with Factor XIIIa. G, the spindle cells of the IMT stained diffusely positively with actin. $\mathbf{H}$, Desmin.

and/or dystrophic calcifications in varying amounts (1). Distinction from IMT may be difficult because spindle cells, an inflammatory infiltrate, and some- times calcifications characterize both CFP and IMT. Indeed, Coffin et al. $(7,17)$ has commented that IMT represents but one form in a morphologic 


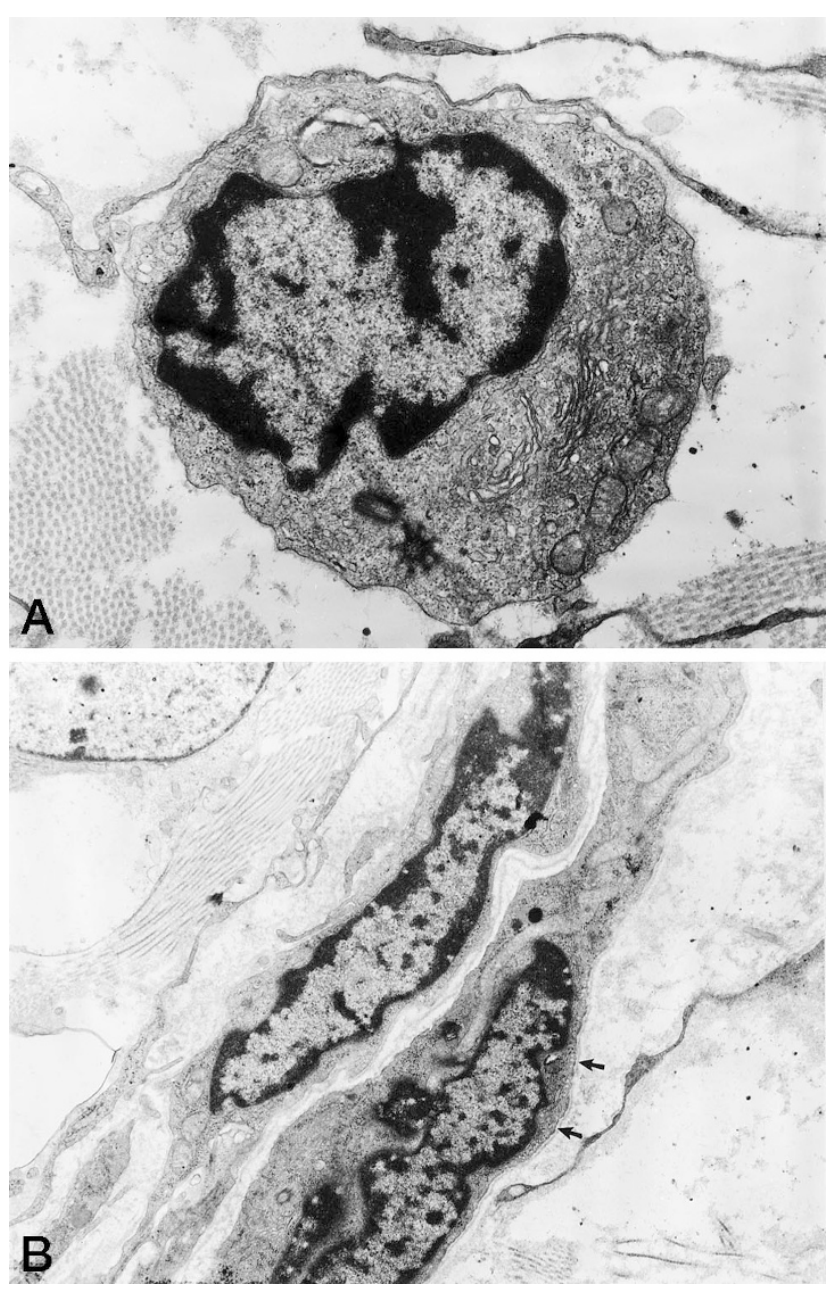

FIGURE 2. A, electron microscopy of calcifying fibrous pseudotumor contains spindle cells with intermediate filaments and collagen fibrils showing the fibroblastic nature of the cells. B, electron microscopy of inflammatory myofibroblastic tumor shows filamentous bundles, attachment densities, pinocytotic vesicles, and basal laminae, consistent with myofibroblastic differentiation.

spectrum that includes several inflammatory or reactive tumorlike lesions. Although IMT has been shown to display vascular invasion (7) as well as clonal chromosomal abnormalities in some cases (4), the prognostic significance of these findings remains unknown. Cellular atypia, cells similar to ganglion cells, p53 expression, and DNA aneuploidy were suggestive of lesions with potential for malignant transformation (18).

Coffin et al. (7) documented the histologic transformation of IMT associated with local recurrence. In contrast, CFP has thus far shown an excellent prognosis, with recurrences being rare and showing the same morphology as the primary lesion. The spindle cells of IMT react intensely against antibodies for muscle-specific actin and desmin, which points to the myofibroblastic nature of the cells. Except in our Cases 1 and 2, this reactivity was confirmed for IMT, whereas none of the CFPs stained with muscle-specific actin, smooth muscle actin, or desmin.
A feature not previously described is the focal staining of IMT with Factor XIIIa compared with the diffuse staining of the CFP cases. Factor XIII is a tetrameric protein consisting of two pairs of subunits (two a and two b) with the enzyme activity present in subunit a. Factor XIIIa, a protransglutaminase synthesized by the liver, is involved in the final part of the coagulation pathway via stabilization of clot formation by cross-linking fibronectin to collagen (19). Fixed connective tissue cells, macrophages, histiocytes, and fibroblasts all contain Factor XIIIa, as demonstrated by immunohistochemistry. Cerio et al. (20) hypothesized that these cells are the cells of origin for fibroblastic and phagocytic cells, and that as the cells mature, immunostaining by Factor XIIIa is reduced. In keeping with this contention, CD68 is also positive in CFPs (variable in IMTs), with similar diffuse and granular cytoplasmic staining as that of Factor XIIIa.

Electron microscopy showed features of immature fibroblastic cells in CFP similar to that reported by Maeda et al. (14), whereas the IMT ultrastructure contained primarily myofibroblastic cells and "activated" fibroblasts. The strong reactivity of CFP with Factor XIIIa suggests that this tumor may belong in the group of lesions that show reactivity to Factor XIIIa and are considered "fibrohistiocytic" in origin, including dermatofibroma, Kaposi's sarcoma, fibrous histiocytoma, and fibrous papules $(21,22)$.

Although several authors have alluded to the potential relationship between the Epstein-Barr virus and inflammatory pseudotumor $(23,24)$, we have not been able to detect by immunohistochemical studies any association in either CFPs or IMTs (although we tested only two IMT cases). Mutations of the c-kit gene have been reported in GIST (gastrointestinal stromal tumors), and currently, the expression of the kit ligand (also known as stem cell factor [SCF], Steel factor [SI], or mast cell growth factor) is the most specific marker to delineate GIST from true smooth muscle tumors $(25,26)$. In this study, c-kit expression is not seen in the stromal component but rather is confined to the numerous mast cells in both lesions, although they are more abundant in CFPs. The exact contribution of mast cells in these lesions is largely unknown. However, there is increasing evidence that mast cells are noted in diseases with neovascularization such as wound repair, hemangioma, and vascular malformations, including some tumors $(27,28)$. It seems likely that mast cells, by secreting cytokines or growth factors, contribute to the proliferation of fibroblasts and vessels in these lesions (29). In support of this theory, our findings of increased mast cells in CFPs appear to correlate well with increased microvascular density. 
Our negative CD34 staining in CFPs is at variance with other results of CD34-positive tumors $(30,31)$, whereas we support many with similar results (12, 15, 32). These discrepant results prompted us to reexamine a case of calcifying pseudotumor occurring in the peritoneum, which was found incidentally in a 56-year-old woman with colon cancer (not included in this communication), also CD34 positive. In review, the CD34-positive cases in the literature $(30,31)$ were all from the peritoneum or retroperitoneum, whereas others, as well as our own, were from soft tissue or mediastinum (32).

In conclusion, we believe that the CFPs have distinct features from IMTs and may arise from a pathogenesis distinct from that of EBV-positive inflammatory myofibroblastic tumors. Although some CFPs may have similar features with IMTs, it is important to separate those cases in children, especially those arising from the soft tissue from those occurring secondarily in the retroperitoneum. In the later, the tumor of origin is most likely from the submesothelial fibroblasts. It is interesting that anaplastic lymphoma kinase oncogenes have been found recently in inflammatory myofibroblastic tumor (33). Unlike IMTs, CFPs in deep soft tissue locations have been reported negative for anaplastic lymphoma kinase (34), suggesting that CFP is a different clinicopathologic entity than IMT.

Acknowledgments: The authors thank Dr. John Fetsch of the AFIP in Washington, D.C., Dr. Bill Laskin of Northwestern Memorial Hospital for the provision of case materials, and Dr. Susan Crawford for helping us with our microvascular data.

\section{REFERENCES}

1. Fetsch JF, Montgomery EA, Meis JM. Calcifying fibrous pseudotumor. Am J Surg Pathol 1993;17:502-8.

2. Rosenthal NS, Abdul Karim FW. Childhood fibrous tumor with psammoma bodies. Clinicopathologic features in two cases. Arch Pathol Lab Med 1988;112:798-800.

3. Van Dorpe J, Ectors N, Geboes K, D'Hoore A, Sciot R. Is calcifying fibrous pseudotumor a late sclerosing stage of inflammatory myofibroblastic tumor? Am J Surg Pathol 1999; 23:329-5.

4. Su LD, Atayde-Perez A, Sheldon S, Fletcher JA, Weiss SW. Inflammatory myofibroblastic tumor: cytogenetic evidence supporting clonal origin. Mod Pathol 1998;11:364-8.

5. Meitar D, Crawford SE, Rademaker AW, Cohn SL. Tumor angiogenesis with metastatic disease, N-myc amplification, and poor outcome in human neuroblastoma. J Clin Oncol 1996;14:405-14.

6. Hill KA, Gonzalez-Crussi F, Omeroglu A, Chou P. Calcifying fibrous pseudotumor involving the neck of a five-week-old infant. Presence of Factor XIIIa in the lesional cells. Pathol Res Pract 2000;196:527-31.

7. Coffin CM, Watterson J, Priest J, Dehner LP. Extrapulmonary inflammatory myofibroblastic tumor (inflammatory pseudotumor). A clinicopathologic and immunohistochemical study of 84 cases. Am J Surg Pathol 1995;19:859-72.
8. Beleggia F, Beccia E, Morcaldi M, Fiorentino F, Casillo A, Sperandeo G, et al. Echographic characteristics of calcifying fibrous pseudotumor of the epididymis [Italian]. Arch Ital Urol Androl 1994;66(4 Suppl):53-5.

9. Dumont P, de Muret A, Skrobala D, Robin P, Toumieux B. Calcifying fibrous pseudotumor of the mediastinum. Ann Thorac Surg 1997;63:543-4.

10. Pinkard NB, Wilson RW, Lawless N, Dodd LG, McAdams HP, Koss MN, et al. Calcifying fibrous pseudotumor of pleura: a report of three cases of a newly described entity involving the pleura. Am J Clin Pathol 1996;105:189-94.

11. Reed MK, Margraf LR, Nikaidoh H, Cleveland DC. Calcifying fibrous pseudotumor of the chest wall. Ann Thorac Surg 1996;62:873-4.

12. Hoffmann H, Beaver ME, Maillard AAJ. Calcifying fibrous pseudotumor of the neck. Arch Pathol Lab Med 2000;124: 435-7.

13. Jimenez-Heffernan JA, Urbano J, Tobio R, Capoto LP. Calcifying fibrous pseudotumor: a rare entity related to inflammatory pseudotumor. Acta Cytol 2000;44:932-4.

14. Maeda T, Hirose T, Furuya K, Kameoka K. Calcifying fibrous pseudotumor: an ultrastructural study. Ultrastruct Pathol 1999;23:189-92.

15. Dargent JL, Delplace J, Roufosse C, Laget JP, Lespagnard L. Development of a calcifying fibrous pseudotumor within a lesion of Castleman disease, hyaline-vascular subtype. J Clin Pathol 1999;52:547-9.

16. Bahadori M, Liebow AA. Plasma cell granulomas of the lung. Cancer 1973;1973:31:191-208

17. Coffin CM, Dehner LP, Meis-Kindblom JM. Inflammatory myofibroblastic tumor, inflammatory fibrosarcoma, and related lesions: an historical review with differential diagnostic considerations. Semin Diagn Pathol 1998;15:102-10.

18. Hussong JW, Brown M, Perkins SL, Dehner LP, Coffin CM. Comparison of DNA ploidy, histologic and immunohistochemical findings with clinical outcome in inflammatory myofibroblastic tumors. Mod Pathol 1999;12(3): 279-86.

19. Mosher DF, Schad PE, Vann JM. Cross linking of collagen and fibronectin by factor XIIIa. Localization of participating glutaminyl residues to a tryptic fragment of fibronectin. J Biol Chem 1980;255:1181-8.

20. Cerio R, Spaull J, Jones EW. Histiocytoma cutis: a tumor of dermal dendrocytes (dermal dendrocytoma). Br J Dermatol 1989;120:197-206.

21. Gray MH, Smoller BR, McNutt NS, Hsu A. Giant dermal dendrocytoma of the face: a distinct clinicopathologic entity. Arch Dermatol 1990;126:689-90.

22. Nickoloff BJ, Wood GS, Chu M, Beckstead JH, Griffiths CEM. Disseminated dermal dendrocytomas. A new cutaneous fibrohistiocytic proliferative disorder? Am J Surg Pathol 1990; 14:867-71.

23. Arber DA, Kamel OW, van de Rijin M, Davis RE, Medeiros LJ, et al. Frequent presence of the Epstein-Barr virus in inflammatory pseudotumor. Hum Pathol 1995;26:1093-8.

24. Selves J, Meggetto F, Brousset P, Voigt JJ, Pradere B, Grasset $\mathrm{D}$, et al. Inflammatory pseudotumor of the liver. Evidence for follicular dendritic reticulum cell proliferation associated with clonal Epstein-Barr virus. Am J Surg Pathol 1996;20: 747-53.

25. Hirota S, Isozaki K, Moriyama $\mathrm{Y}$, Hashimoto K, Nishida T, Ishiguro S, et al. Gain-of-function mutations of c-kit in human gastrointestinal stromal tumors. Science 1998;279:57780 .

26. Miettinen M, Sarlomo-Rikala M, Sobin LH, Lasota J. Gastrointestinal stromal tumors and leiomyosarcomas in the colon. Am J Surg Pathol 2000;24:1339-552.

27. Rother MJ, Nowak M, Kerdel FA. The mast cell in health and disease. J Am Acad Dermatol 1990;23:615-24. 
28. Meninger CJ, Zetter BR. Mast cells and angiogenesis. Semin Cancer Biol 1992;3:73-9.

29. Kessler DA, Langer RS, Pless NA, Folkman J. Mast cells and tumor angiogenesis. Int J Cancer 1976;54:459-65.

30. Zamecnik M, Michal M, Boudova L, Sulc M. CD34 expression in calcifying fibrous pseudotumors. Histopathology 2000;36: 182-91.

31. Weynand B, Draguet AP, Bernard P, Marbaix E, Galant C. Calcifying fibrous pseudotumor: first case report in the peritoneum with immunostaining for CD34 [letter]. Histopathology 1999;34:86-7.
32. Fukunaga M, Kikuchi Y, Endo Y, Ushigome S. Calcifying fibrous pseudotumor. Pathol Int 1997;47:60-3.

33. Lawrence B, Perez-Atayde A, Hibbard MK, Rubin BP, Dal Cin $\mathrm{P}$, Pinkus JL, et al. TPM3-ALK and TPM4-ALK oncogenes in inflammatory myofibroblastic tumors. Am J Pathol 2000;157: 377-84.

34. Sigel JE, Smith TA, Reith JD, Goldblum JR. Immunohistochemical analysis of anaplastic lymphoma kinase expression in deep soft tissue calcifying pseudotumor: evidence of a late sclerosing stage of inflammatory myofibroblastic tumor? Ann Diagn Pathol 2001;5:10-4.

\section{Book Review}

Duckett, S, De La Torre, JC, editors: Pathology of the Aging Human Nervous System. Second Edition 624 pp, New York, Oxford University Press 2000 (\$119.00).

Pathology of the Aging Human Nervous System is an updated version of the book originally edited by Dr. Serge Duckett and J.C. De La Torre. It describes pathologic aspects of aging in a manner that is useful not only to pathologists, clinicians, and researchers, but also to individuals from other disciplines with a personal or professional interest in aging. The contributing authors are comprised of international leaders in their respective areas of expertise. Each author has included not only historical and general reference material, but also up-to-date information regarding recent advances in the field. Introductory chapters discuss epidemiological trends and features of successful aging; however, the pri- mary purpose of this book is to provide a comprehensive description of age-related changes occurring in brain, spinal cord, peripheral nerve, and skeletal muscle. Clinical, gross, microscopic, molecular, and genetic aspects of aging are discussed in the context of specific diseases ranging from neurodegenerative diseases to forensic to infectious diseases. This book is organized by diagnosis so that readers with a particular field of interest can easily read about the age-related aspects of virtually any neuropathologic process. This is an authoritative, clearly written book that engages the reader by using simple, professional language and by covering material that is of interest to anyone currently participating in the aging process.

\section{Karen SantaCruz \\ University of Kansas Medical Center}

